\title{
Five Years of Translation Publishing
}

By EDWARD P. TOBER

$\mathrm{T}$ he American Institute of Physics is completing the first five years of its cover-to-cover translation program and, as befits an anniversary, has recently been occupied with some glancing back and peering forward. Both views will probably interest many American research librarians.

Much of the groundwork for the present program was prepared in 1954 by Dwight Gray, now program director for publications and information services of the National Science Foundation, and Elmer Hutchisson, now director of the AIP. A survey in that year of a segment of the American Physical Society revealed an unmistakable need for a wider dissemination of the results of Soviet research. More than half of those responding to the survey questionnaire believed that complete translations were preferable to translation of selected articles.

With the encouragement and support of the NSF, the first issue of Soviet Physics-JETP, the pioneer translation journal, an English language version of the Soviet Academy of Sciences periodical, the Journal of Experimental and Theoretical Physics, was published late in 1955. Its first editor was Dr. Robert $T$. Beyer of Brown University. The list of physics translation journals ultimately grew to eight in all, the most recent addition, Soviet Physics-Solid State, having made its bow last June.

Impetus for the inception and subsequent expansion of the program came, of course, from the inability of most American physicists to read Russian. Of the 18,000 physicists on the 1954 NSF roster, less than 2 per cent (189) had an adequate reading proficiency in Russian, as contrasted with 45 per cent for German.
Mr. Tober is Manager, Production and Distribution, American Institute of Physics, Inc., New York.

A more recent analysis, incidentally, showed no real change in this respect. In the 1956-58 register, which included some 23,000 physicists, the proportion was still less than 2 per cent (397). The consensus is that this percentage will not greatly increase in the near future.

It is a source of much satisfaction to those connected with the program that the increased accessibility of the Soviet material resulting from Institute translation journal publishing has been associated with a striking rise in its use. The aforementioned Journal of Experimental and Theoretical Physics has been available in translation to a significant number of physicists since mid-1956. A recent Institute study of citations to this journal in the 1956 and 1959 issues respectively of The Physical Review shows a nearly five-fold increase in the latter year.

The worth of this additional knowledge to American physicists is, of course, difficult to assess precisely in dollar terms or otherwise. But the many expressions of encouragement and support received right from the outset of the program indicate that these translations of Russian journals of primary research do represent an effective contribution to scientific effort in the West.

Recent response from the physics community suggests that in the last year there has been a sharply heightened awareness of the value of keeping informed on the Soviet output. The past twelve months 
have seen the subscription totals of all of the journals increase sharply; all but one are well over the five-hundred mark. The Soviet Physics-JETP subscription list now approximates one-thousand. Subscription prices now range from approximately one to two and one-half cents per page, nonprofit academic libraries taking the lower rate.

When related to the benefits of the program, the cover-to-cover translation journals are viewed as a relatively inexpensive means of acquiring the results of much valuable research. In absolute terms, of course, the program is not without its cost. But until such time as a knowledge of Russian is much more widespread or until machine translation is perfected, the most effective method of communicating Soviet developments to the West would appear to be by the delivery to the scientist, five to seven months after publication of the originals, the authoritative, complete translations. The rising use of the latter points to a firm acceptance of the present translation program by the physicist and the research librarian who serves him.

\section{We Chose Microfilm}

(Continued from page 226)

plete. Since the paper issues are not sent away for processing as in binding, the library always has a complete file available for use. Both the Colby and Baldwin libraries dispose of the magazines which have been replaced by microfilm.

In comparing notes, Colby and Baldwin agree on the advantages and disadvantages of microfilm except for one item. Colby feels that films are easier to use since one does not have to handle weighty volumes of periodicals. Baldwin considers bound volumes slightly easier to use since the librarian does not have to give instructions in film reader operation and since a page is easier to find than a frame of microfilm. To see the frame-finding problem, one must realize that microfilm is stored on hundred-foot reels which accommodate twelve issues of monthly magazines, and in using microfilm one always starts at the front of the reel. For example, if the November issue is wanted, one must reel through January, February, March, etc., to reach November. The experienced microfilm reader soon learns to "watch for the cover," which is a single page frame causing a light flick and enabling one to count months while winding film at a rapid rate, and so find the right month with a minimum of time; but frequently the beginning microfilm user complains that it takes him several minutes to find the right frame. However, Baldwin considers this a minor complaint.

One unexpected advantage that came to Baldwin and Colby from their microfilm programs is that both are able to provide microfilm readers for faculty and non-college personnel borrowing or buying microfilm materials in connection with research or graduate study. Colby feels that this has made many offcampus people friends of its library.

The librarians of Baldwin and Colby are pleased with the space and moneysaving features of microfilm and consider it an excellent solution to many problems involved in keeping and in using back issues of periodicals, especially in the small library which is limited in space, staff, and funds. Most students are intrigued by microfilm and delight in finding opportunities to use it. 